\title{
Going Public, Going Global: Teaching Public History Through International Collaborations
}

$\mathrm{I}$

n July 2014, the first Public History Faculty Training Program in China took place in Shanghai, as a result of partnerships between Shanghai Normal University and Princeton University. The program covered many areas of common ground in Chinese and American cultures, including public history and public/social memory, oral history, museums, archives, urban landscapes, historic preservation, new media, civic engagement, curriculum design and program development. The original objective was to introduce participants to the field of public history, conceptually, practically and pedagogically. The two-week collaborative endeavor also offered opportunities for student and faculty exchanges in an intensely cross-cultural context, which

\footnotetext{
Public History Review

Vol 22 (2015): 1-7

ISSN: $1833-4989$

@ 2015 by the author(s). This is an Open Access article distributed under the terms of the Creative Commons Attribution 4.0 International (CC BY 4.0) License (https://creativecommons.org/licenses/ by/4.0/), allowing third parties to copy and redistribute the material in any medium or format and to remix, transform, and build upon the material for any purpose, even commercially, provided the original work is properly cited and states its license.
} 
provided valuable perspectives on how public history is interpreted differently in two cultures.

While collaboration is a regular component of public history programs, going global poses further challenges. First, language barriers and cultural misunderstanding create confusion - even breakdowns throughout the collaborative process. Second, different pedagogic philosophies make some basic assumptions in our field not so basic. Sharing authority, for example, does not come easily in classrooms that have long been dominated by one authoritative voice. Third, it is difficult to provide valid intellectual justification for training in public history if the field is attached to a strictly market-driven economy and services a commercial vision. Fourth, different sets of legal and ethical concerns sometimes complicate, if not stifle, genuine dialogue.

Thinking about possible ways to address these challenges, I initiated a working group on the issue of teaching public history through international collaborations for the National Council on Public History 2015 annual meeting. Jann Warren-Findley, the original co-facilitator, and I met in Chongqing in November 2014 to lay out the basic framework for this panel. With extensive experience in public history projects outside the United States, Jann had been actively involved in building up the partnership between Arizona State University's Public History Program and Sichuan University's American Studies Program since 2010. Her unexpected death in January 2015 left us many unstated yet valuable lessons. Rebecca Conard, a veteran public historian leading a successful public history program at Middle Tennessee State University, generously offered her help. Rebecca and I worked together and convened the Working Group on Teaching Public History through International Collaborations at the National Council on Public History meeting in Nashville, Tennessee, in April 2015.

\section{OBJECTIVES}

We have had four objectives for this working group. Our first was to understand specific public history projects in a cross-cultural context, and discuss the possibilities of maturing the collaborative efforts into cases for teaching public history. Second, we aimed to utilize local resources to create cross-cultural public history projects, such as museums, archives and urban preservations, and address specific challenges in these collaborations. Third, we aimed to understand the broad framework that drives the conversations to move from local to global, when they sometimes become, counter-intuitively, more narrowly focused and end with the simplified label 'cultural differences'. 
Finally, we aimed to tease out factors that help sustain international collaborations, as most public history projects are catalytic, instead of conclusive.

Six participants and the audience produced a thoughtful and productive discussion in Nashville. We asked the participants to add further intellectual strength, and turn their case statements into short articles, four of which follow.1 Like the first Public History Faculty Training Program in China, these collaborative efforts take place as the field of public history starts to take an international turn in the twenty first century. The ensuing four articles, covering Britain, South Africa, Morocco and Brazil, tackle different public history issues, at various scales, in specific international settings. Taken together, they contribute to the four goals listed above.

\section{QUARTET}

Elizabeth Catte discusses her experience as a foreign heritage worker on the Isle of Man, a small, quasi-independent island in the middle of the Irish Sea. She argues that the Isle of Man deploys what it sees as a universally accessible and consumable heritage brand as a way to create social stability among a diverse and rapidly changing population by offering opportunities to forge a shared identity through the celebration of its unique culture. Her analysis of cultural difference, definition of community, understanding of civic engagement and heritage construction intricately links with her own national and cultural identity.

Britney Ghee takes us to Ghana. She examines her international experience as a researcher and an intern working in the National Museum of Ghana. Her obroni analysis emphasizes the importance of self-reflection when examining museum narratives and challenges the current method of creating individual exhibitions and then fitting them into the museum's larger narrative. She discusses the importance of understanding the history and development within international discourses of public history in order to truly collaborate. She also notes that, for collaborations to flourish, each contributor must understand and appreciate the differences within public historiographies to truly understand where approaches converge and diverge.

Both Elizabeth Catte and Britney Ghee have directly engaged in public history projects in cultures outside the United States. Their pieces raise many transnational issues that deserve a close reading by those who are interested in working on international public history projects. Critiquing 'authorized heritage discourse' on the Isle of Man, Elizabeth Catte pens her argument on the conflicting priorities in branding the 
Island's heritage in the global economy, and how a sense of 'otherness' permeates and shapes its identity. The author's own identity as an outsider gives her a critical distance to observe and to participate, and it may also make the reader wonder how her 'foreign' status affects her focus of observations and subsequent interpretations. Similarly, walking us through the five sections in the National Museum of Ghana, Britney Ghee's obroni - foreigner or non-African - perspectives also raise the identity issue. The Ghana experience humbles her, and her concluding thoughts about 'approaching issues with cultural differences in mind' seem quite fitting. As a part of her thesis research, her piece suggests further potential for developing quality international internships in regular public history programs.

Richard Harker's discussion on Museums Connect, a program funded by the US Department of State and administered by the American Alliance of Museums that sponsors transnational museum partnerships, takes up the challenges we face in international collaborations at a different scale. His article, with detailed analysis of the projects involved two university museums - the Museum of History and Holocaust Education (MHHE) in the United States and the Ben M'sik Community Museum (BMCM) in Morocco - from 2009 to 2012, suggests a model for teaching public history in a transnational context. An unbalanced power distribution, for example when one partner possesses significantly more professional expertise, presents challenges to a sustainable relationship. In Harker's work, we see actual collaborations take place at institutional levels, which epitomizes and challenges the very idea of 'sharing authority' in all phases and details. To sustain a complicated transnational partnership such as Museum Connect, public historians need extra humility, as he cautions, 'it is naïve to assume ideas of one culture to be uncritically absorbed by another culture'.

Among many challenges in Museum Connect, Richard Harker tangentially discusses language barriers and cultural misunderstandings that can make or break international collaborations. Karina Esposito takes up this point, and explores further. She analyzes the immigration of confederates to Brazil during and after the Civil War, and how the descendants residing in Brazil today remember and commemorate their American, Brazilian and Confederate heritage. She notes that language barriers and cultural misunderstanding often affect cross-cultural identity, memory and commemorative practices, and advocates a global perspective in teaching public history. Pedagogically, she encourages students to take on subjects with a transnational perspective, to interpret primary sources and understand multinational historiographies. 


\section{REFLECTIONS}

Despite different worldviews, social traditions and geographic focus, public history issues are often arrestingly similar across cultures. Issues revealed in the four articles echo my own experience of working on behalf of a Chinese university with an American university on the public history faculty training program. Both sides spent a lot of time communicating and adjusting draft programs, trying to work the best out of mutual interests. Time differences, institutional bureaucracies, different planning landscapes and expectations all posed challenges. During the two-week program, I also encountered many 'surprises'. A visit to Nanjing Massacre Memorial Hall, for example, provoked an animated debate. Displaying the actual bones of the victims in the recently re-designed memorial hall generated 'cultural wars' between Chinese and American participants. For Chinese, those bones were authentic artefacts, powerful forensic evidence to prove the massacre actually happened. For Americans, the graphic display constituted a shameful disrespect for the dead. Here we were not struggling for a frontal attack on the controlling and univocal official narratives in a particular culture, but for a public space that engages different cultural voices.

As someone who has regularly travelled between the United States and China, I realized that if the program had been conducted in a purely Chinese setting, with an emotional assumption of a shared community, the issue would never have come out. It became a source of cultural conflict in the transnational dialogues, with certain historical messages confused or lost when cultural values crisscrossed.

So what do we need in international collaborations? Points that come readily to mind include:

Mutual research interests and complementary expertise on the project;

Institutional commitment, which sustains collaboration

Cross-cultural skills, which involve a genuine respect for a different culture, a solid grasp of both cultures involved in the project, language fluency and cultural sensitivity and

Political savvy, which refers to the practical intelligence to negotiate among power differentials and dynamics in a politically charged environment. 
These skills need to be acquired through 'shoving the dirt'. We cannot expect those who have never travelled outside one's own country to demonstrate genuine 'cross-cultural' sensitivity. It is easy to talk about respecting another culture, but action takes more than a willingness of heart. Yet, like other skills, respect gets easier with practice. Here the responsibility lies primarily with someone with a cross-cultural background to work as a gatekeeper, a facilitator or a negotiator. Also, the pedagogical implications encourage public history educators to develop international collaborative projects or internships. The 'Comparative Public History, US and UK' program at the University of South Carolina, a residential program (England Field School) based in North Yorkshire, England, stands as an excellent example. This thirtyyear-old program reinforces many issues revealed in this special section.

\section{LOOKING AHEAD}

This special section presents neither a comprehensive nor a balanced picture of international collaborations on public history. Part of the challenge in in-depth discussions on teaching public history through international collaborations lies in the fact that very few collaborations are truly international. Dialoguing with public historians in another country may provide valuable perspectives, and possibly comparative lessons. Yet conversations do not equal actual practices. Transplanting public history experience from one culture to another does not automatically render it 'international'. As public history is collaborative in nature, it is also deeply local and contextual. This raises the concern about how far we can go in international collaborations.

When it comes to the challenges, we seem to ask more questions than provide answers. Looking ahead, we need more well-researched analysis on issues related to legal and ethical concerns, social values and cultural idiosyncrasies, institutional expectations and pedagogical implications. While it remains to be seen whether many developing collaborations will mature into successful cases for teaching public history, public history remains collaborative and it continues to push back its borders, be they national, cultural or disciplinary.

\section{ACKNOWLEDGEMENTS}

The National Social Science of China (Project Number: 14XSS007) and Interdisciplinary Research Projects in Humanities and Social Sciences, Chongqing University (Project number: CDJKXB14008) funded my travel to Nashville in April 2015 for this Working Group. The author would like to thank Paul Ashton for his patient guidance and valuable advice through the entire process of preparing this special section. 


\section{Endnotes}

${ }^{1}$ I asked the authors to either describe a particular circumstance at a greater length than was allowed by the case-statement structure, with an illustration or two if appropriate, or argue a particular point with more focus and clarity. I appreciate all four authors' willingness to revise their drafts in response to my comments and to those of reviewers selected by the editors of Public History Review. 